\title{
Plasma and urine cyclic nucleotide levels in malignant disease and cirrhosis of the liver
}

\author{
P. J. WOOD ${ }^{1}$, GILLIAN ROSS, AND C. L. SMITH \\ From the Departments of ${ }^{1}$ Chemical Pathology and Medicine II, Southampton University Hospitals, \\ Southampton, Hants, UK
}

SUMMARY Plasma and 24-hour urinary cyclic AMP and cyclic GMP levels were determined by saturation analysis in specimens from normal subjects and from 101 patients with tumours of the gastrointestinal tract, breast, lung, bladder or prostate, or with cirrhosis of the liver. Relative to 46 control subjects, plasma cyclic GMP concentrations were significantly elevated in seven patients with gastric tumours, 20 patients with cancer of the breast, six patients with lung cancer, and 12 patients with cirrhosis of the liver. Urinary cyclic GMP/creatinine ratios were significantly increased in cirrhotic patients and in the lung and oesophageal cancer groups. In no cancer group were increases in plasma or urine cyclic GMP levels sufficiently consistent to be of value in the diagnosis of human malignant disease. Changes in extracellular fluid cyclic nucleotide levels in the cirrhotic group were very similar to those that have been reported for primary hepatoma patients.

Cyclic 3',5'-adenosine monophosphate (cyclic AMP) is a well-established second messenger for hormone stimulation of target cells. The exact role played by cyclic 3',5'-guanosine monophosphate (cyclic GMP) in the regulation of cell metabolism is still far from clear (Goldberg and Haddox, 1977). In some tissues, cyclic GMP can oppose the action of cyclic AMP in cell control processes. It is known from cell culture studies that increases in cyclic GMP concentrations are associated with cell proliferation, whereas high cyclic AMP levels inhibit cell growth (Goldberg et al., 1975).

Cyclic GMP/cyclic AMP ratios in rat liver and kidney tumour tissue are high relative to uninvolved liver or renal tissue, the highest ratios being associated with the fastest growing tumours (Criss and Murad, 1977). Increased urinary excretion of cyclic GMP has been reported in rats bearing transplantable liver and kidney tumours (Criss and Murad, 1976). Cyclic GMP excretion in rats with Morris hepatoma 3924A correlated with tumour size and decreased in parallel with the efficacy of surgical, radiation, or drug therapy (Murad et al., 1975).

There have been few reports to date of extracellular fluid cyclic GMP levels in human malignant disease. In a preliminary report, Neethling and

Received for publication 4 April 1979
Shanley (1976) described significant elevation of urinary cyclic GMP excretion in three patients with primary hepatoma and suggested that extracellular fluid cyclic nucleotide measurements may be of value in the diagnosis and monitoring of malignancy.

This study was designed to investigate whether other types of human cancer are associated with altered plasma or urine cyclic nucleotide levels, and to determine if such changes could be correlated with tumour size or the presence of metastases. Patients with cirrhosis of the liver were also studied in an attempt to establish the specificity of the reported urinary cyclic GMP increases in primary hepatoma.

\section{Patients and methods}

The numbers and age ranges of the patients who were studied are listed in Table 1. Diagnoses were confirmed by histology of biopsy material or surgical specimens.

Patients with malignant disease were classified according to the type and size of the tumour and the presence of metastases. Of the 28 cases of colorectal cancer, two were classified as Duke's stage A, 11 as stage $B$, eight as stage $C$, and six as stage $C_{2}$ with hepatic metastases evident on tissue biopsy, isotopic scan, or ultrasound. Two of seven patients with gastric cancer were noted to have involved lymph nodes at surgery. Liver metastases were 
Table 1 Patients

\begin{tabular}{|c|c|c|c|c|c|c|c|c|}
\hline \multirow[t]{2}{*}{ Group } & \multicolumn{4}{|c|}{ Plasma } & \multicolumn{4}{|c|}{ 24-hour urine } \\
\hline & Total & $M$ & $\boldsymbol{F}$ & Age range & Total & $M$ & $\boldsymbol{F}$ & Age range \\
\hline $\begin{array}{l}\text { Normal subjects } \\
\text { Ca colon/rectum } \\
\text { Ca stomach } \\
\text { Ca oesophagus } \\
\text { Ca breast } \\
\text { Ca lung } \\
\text { Ca bladder } \\
\text { Ca prostate } \\
\text { Liver cirrhosis }\end{array}$ & $\begin{array}{r}46 \\
28 \\
7 \\
9 \\
20 \\
6 \\
4 \\
12\end{array}$ & $\begin{array}{r}12 \\
14 \\
4 \\
6 \\
4 \\
- \\
10\end{array}$ & $\begin{array}{r}34 \\
14 \\
3 \\
3 \\
2 \\
-\end{array}$ & $\begin{array}{l}19-60 \\
29-75 \\
58-72 \\
48-79 \\
35-65 \\
42-70 \\
\overline{60-75} \\
40-68\end{array}$ & $\begin{array}{r}36 \\
25 \\
6 \\
8 \\
18 \\
5 \\
8 \\
2 \\
13\end{array}$ & $\begin{array}{r}10 \\
12 \\
4 \\
6 \\
-4 \\
8 \\
10\end{array}$ & $\begin{array}{r}26 \\
13 \\
2 \\
2 \\
1 \\
- \\
3\end{array}$ & $\begin{array}{l}24-60 \\
29-75 \\
58-72 \\
48-79 \\
35-63 \\
42-60 \\
28-70 \\
68-75 \\
40-68\end{array}$ \\
\hline
\end{tabular}

evident in two of nine patients with oesophageal carcinoma. Widespread bony metastases were present in five of the 20 patients with carcinoma of the breast.

The liver cirrhosis group consisted of 10 patients with alcoholic cirrhosis and three patients with cirrhosis associated with $\alpha_{1}$-antitrypsin deficiency.

Control subjects were healthy volunteers or women who were found to have benign fibroadenomata of the breast on histological examination of breast biopsy tissue.

All plasma and urine specimens were collected from patients before the start of treatment or surgery. Aliquots of 24-hour urines were stored frozen until they were analysed. Blood $(20 \mathrm{ml})$, obtained by venepuncture between 0900 and 1100 , was rapidly added to two lithium heparin tubes (10 IU heparin/ml blood), one of which also contained EDTA $(0.5 \mathrm{~mol} / 1 \mathrm{pH} 7.4 ; 100 \mu \mathrm{l}$ per $10 \mathrm{ml}$ of whole blood). Plasma from the tube containing EDTA was rapidly separated and stored at $-20^{\circ} \mathrm{C}$ until analysed. Plasma separated from the tube containing heparin only was incubated at $37^{\circ} \mathrm{C}$ for 1 hour. In this way plasma cyclic nucleotides were degraded by endogenous cyclic nucleotide phosphodiesterase enzyme to give a 'blank' plasma sample for each patient.

Plasma and urine cyclic GMP levels were determined by direct radioimmunoassay (Wood and Marks, 1978). Plasma and urine cyclic AMP concentrations were measured by methods based on the adrenal protein kinase binding assay of Brown et al. (1971) with the inclusion of cyclic AMP-free plasma in standardisation tubes to compensate for protein effects. Between-batch precisions for the plasma and urine cyclic nucleotide assays are set out in Table 2. Urine creatinines were determined by the alkaline picrate method on an AutoAnalyser.

The statistical significance of results was assessed using the non-parametric Mann-Whitney ' $U$ ' test. Very similar levels of significance were also obtained by $\log$ transformation of group data and comparison by Student's $t$ test.

\section{Results}

The mean levels and $95 \%$ confidence limits for urine and plasma cyclic nucleotide results for control subjects are listed in Table 3.

Although several patients in the cancer and cirrhosis groups had very high plasma cyclic GMP concentrations (Fig. 1) there was considerable overlap with the control data. Plasma cyclic GMP levels in the stomach, breast, lung, and cirrhosis groups were significantly higher than those for the control subjects. Plasma cyclic GMP/cyclic AMP ratios showed a similar pattern (Fig. 2). Plasma cyclic AMP levels in the cancer patients (not shown) were not significantly different from normal levels, although in the cirrhotic patients plasma cyclic AMP levels were significantly higher than in the control group.

Table 2 Inter-assay precisions for cyclic nucleotide assays

\begin{tabular}{|c|c|c|c|c|c|}
\hline & & & No. of assays & Mean result & $C V(\%)$ \\
\hline Plasma & $\begin{array}{l}\text { cyclic AMP } \\
\text { cyclic GMP } \\
\text { cyclic AMP } \\
\text { cyclic GMP }\end{array}$ & $\begin{array}{l}\text { QC1 } \\
\text { QC2 } \\
\text { QC1 } \\
\text { QC2 } \\
\text { QC1 } \\
\text { QC2 } \\
\text { QC1 } \\
\text { QC2 }\end{array}$ & $\begin{array}{r}7 \\
7 \\
12 \\
12 \\
10 \\
10 \\
10 \\
10\end{array}$ & $\begin{array}{c}3.9 \mathrm{pmol} / \text { tube } \\
5.0 \mathrm{pmol} / \text { tube } \\
0.9 \mathrm{pmol} / \text { tube } \\
4.7 \mathrm{pmol} / \mathrm{tube} \\
5.0 \mathrm{nmol} / 1 \\
10.4 \mathrm{nmol} / 1 \\
1.0 \mathrm{nmol} / 1 \\
2.2 \mathrm{nmol} / 1\end{array}$ & $\begin{array}{r}10 \cdot 8 \\
8 \cdot 2 \\
6 \cdot 7 \\
7 \cdot 3 \\
10 \cdot 9 \\
9 \cdot 8 \\
12 \cdot 3 \\
9 \cdot 8\end{array}$ \\
\hline
\end{tabular}


Table 3 Plasma and urine cyclic nucleotide levels-normal subjects

\begin{tabular}{|c|c|c|c|c|}
\hline & & $N$ & Mean & $95 \%$ Confidence limits \\
\hline Plasma & $\begin{array}{l}\text { cyclic AMP } \\
\text { cyclic GMP } \\
\text { cyclic GMP/cyclic AMP } \\
\text { cyclic AMP† } \\
\text { cyclic GMP† } \\
\text { cyclic AMP/cyclic GMP† }\end{array}$ & $\begin{array}{l}46 \\
46 \\
46 \\
36 \\
36 \\
36\end{array}$ & $\begin{array}{l}9.5 \mathrm{nmol} / 1 \\
2.7 \mathrm{nmol} / 1 \\
0.30 \\
2.6 \mu \mathrm{mol} / \mathrm{g} \text { creat. } \\
0.36 \mu \mathrm{mol} / \mathrm{g} \text { creat. } \\
0.14\end{array}$ & $\begin{array}{l}5 \cdot 4-16.8 \mathrm{nmol} / 1 \\
1 \cdot 1-6 \cdot 5 \mathrm{nmol} / 1 \\
0 \cdot 10-0.90 \\
1 \cdot 2-5 \cdot 4 \mu \mathrm{mol} / \mathrm{g} \text { creat. } \\
0 \cdot 21-0.90 \mu \mathrm{mol} / \mathrm{g} \text { creat. } \\
0 \cdot 04-0.45\end{array}$ \\
\hline
\end{tabular}

*After log transformation of data †24-hour collections

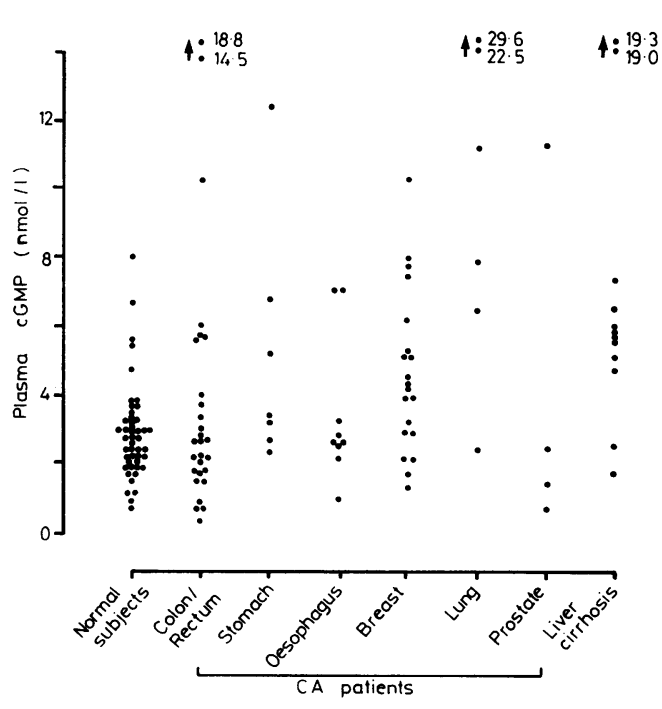

Fig. 1 Plasma cyclic GMP.

Urinary cyclic GMP/creatinine ratios were high in several patients (Fig. 3) although results were significantly higher than normal in only the oesophageal and lung cancer groups and the cirrhotic patients. The calculation of urinary cyclic GMP/ cyclic AMP ratios (Fig. 4) did not improve the discrimination between control subjects and tumour patients. There were no significant differences in urinary cyclic AMP/creatinine levels in any of the patient groups compared with the control data.

The main findings of the study are summarised in Table 4 together with significance levels.

There was no correlation between plasma cyclic GMP and plasma cyclic AMP or between urine cyclic GMP/creatinine and urine cyclic AMP/ creatinine ratios in patients in the groups investigated. There was no correlation between altered extracellular fluid cyclic nucleotide levels and tumour size or metastasis in any of the cancer patient groups.

\section{Discussion}

It is clear from the present study that plasma or urinary cyclic GMP levels or cyclic GMP/cyclic AMP ratios are of little value in the diagnosis of malignancy in spite of the fact that several individuals had strikingly high results. Although these individual high levels could reflect an increased output of cyclic GMP by tumour tissue, the finding from selected animal tumour lines that urinary cyclic GMP output is influenced by the presence and size of a tumour (Murad et al., 1975) does not appear to be generally true for human malignant disease. The results of this study are compatible with the reported wide variation in total cyclic GMP/cyclic AMP ratios in a number of tumour tissues (Goldberg et al., 1975) and are supported by the report of Murad (1978), who found wide variations in plasma and urine cyclic GMP levels 
Table 4 Summary of results

\begin{tabular}{|c|c|c|c|c|c|c|}
\hline \multirow[t]{2}{*}{ Group } & \multicolumn{3}{|l|}{ Plasma } & \multicolumn{3}{|c|}{ 24-hour urines } \\
\hline & $c A M P$ & $c G M P$ & $c G M P / c A M P$ & $c A M P \dagger$ & $c G M P \dagger$ & $c G M P / c A M P$ \\
\hline $\begin{array}{l}\text { Ca colon/rectum } \\
\text { Ca stomach } \\
\text { Ca oesophagus } \\
\text { Ca breast } \\
\text { Ca lung } \\
\text { Ca bladder } \\
\text { Ca prostate } \\
\text { Liver cirrhosis }\end{array}$ & $\begin{array}{l}\text { NS } \\
\text { NS } \\
\text { NS } \\
\text { NS } \\
\text { NS } \\
\overline{N S} \\
\uparrow\end{array}$ & $\begin{array}{l}\text { NS } \\
\uparrow^{*} \\
\text { NS } \\
\uparrow^{* *} \\
\uparrow^{* *} \\
\underset{\uparrow}{N} \\
\uparrow^{* * *}\end{array}$ & $\begin{array}{l}\text { NS } \\
\text { NS } \\
\text { NS } \\
\uparrow^{* *} \\
\uparrow^{* *} \\
\operatorname{NS}_{\uparrow}^{* *}\end{array}$ & $\begin{array}{l}\text { NS } \\
\text { NS } \\
\text { NS } \\
\text { NS } \\
\text { NS } \\
\text { NS } \\
\text { NS } \\
\text { NS }\end{array}$ & $\begin{array}{l}\text { NS } \\
\text { NS } \\
\uparrow^{*} \\
\text { NS } \\
\uparrow^{* * *} \\
\text { NS } \\
\text { NS } \\
\uparrow^{* *}\end{array}$ & $\begin{array}{l}\text { NS } \\
\text { NS } \\
\uparrow^{*} \\
\text { NS } \\
\text { NS } \\
\text { NS } \\
\text { NS } \\
\uparrow^{* * *}\end{array}$ \\
\hline
\end{tabular}

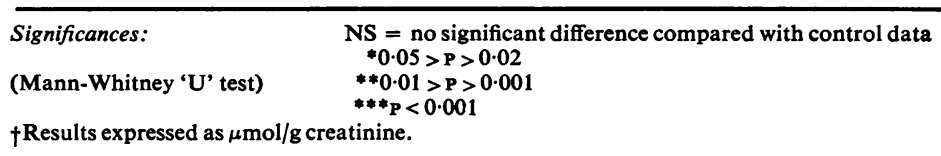

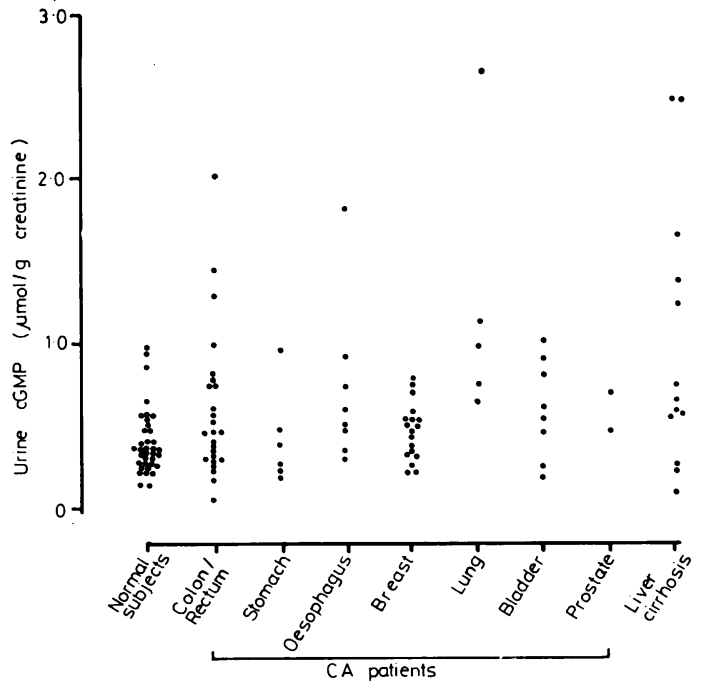

Fig. 3 Urine cyclic GMP.

in a preliminary study of patients with malignant disease.

The observation that plasma and urinary cyclic AMP concentrations were unchanged in all of the malignancy groups relative to control subjects is supported in part by Bershtein and colleagues (1976), who found no differences in urinary cyclic AMP excretion between patients with breast or lung cancer and control subjects in a study of 150 people. Recently, Gennari et al. (1978) have reported a significant decrease in urinary cyclic AMP/ creatinine ratios in patients with a variety of epithelial tumours. These same authors a'so reported abnormally high urinary cyclic GMP/creatinine ratios in 26 patients who were selected on the basis of a low cyclic AMP excretion. Such an inverse

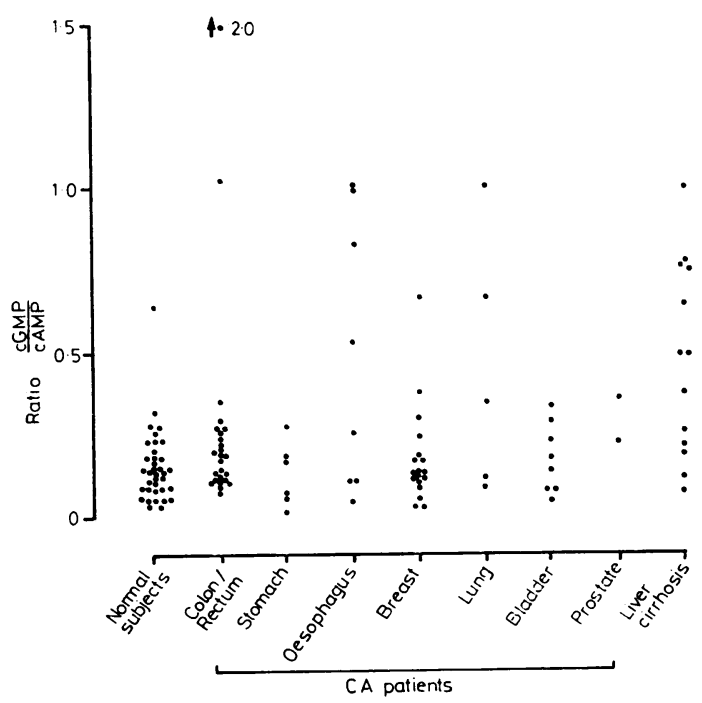

Fig. 4 Urine $\frac{\text { cyclic } G M P}{\text { cyclic } A M P}$ ratios.

relationship between urinary cyclic AMP and cyclic GMP excretion was not established for any group in the present study, and the reason for this discrepancy is unclear.

Although it would be of interest to monitor changes in urinary cyclic nucleotide excretion after surgical removal of a tumour, the fact that trauma results in an increased excretion of cyclic AMP (Vitek et al., 1976) and that urinary cyclic GMP levels may be raised for at least a week after surgery (P. J. Wood et al., unpublished observations) complicates studies in the postoperative period.

The finding of raised plasma and urinary cyclic GMP levels in cirrhotic patients is particularly 
interesting in view of the fact that these changes correlate closely with those reported by Neethling and Shanley (1976) and Murad (1978) in patients with primary hepatoma. It is possible, therefore, that the extracellular fluid cyclic nucleotide changes that have been reported for primary hepatoma patients are associated with a deranged liver metabolism rather than with the tumour tissue itself. The cause of increased plasma and urinary cyclic GMP content in cirrhosis is not clear, although possible contributing factors could be secondary proliferative changes within the liver, decreased hepatic uptake of circulating nucleotides, or changes secondary to a diminished catabolism of a hormone or other agent which can generate cyclic GMP within target cells. At present the picture of a moderate rise in plasma cyclic AMP in addition to a larger increase in plasma and urine cyclic GMP levels could best be interpreted in terms of diminished hepatic uptake of cyclic nucleotides, especially in the case of cyclic GMP. There is some evidence that the liver may take up cyclic GMP in preference to cyclic AMP (Exton et al., 1971; Levine, 1973), and this could explain a possible greater influence of decreased hepatic uptake on extracellular fluid cyclic GMP levels. There was, however, no correlation between plasma alkaline phosphatase or $\gamma$-glutamyl transferase enzyme activities and plasma or urine cyclic GMP levels for the cirrhotic patients.

The results indicate that liver disease is associated with increases in plasma and urine cyclic GMP levels, and that further studies in this area may be worthwhile. Although the investigation of tissue cyclic nucleotide metabolism will continue to provide valuable information in the field of cancer research, this study has shown that the measurement of urinary or plasma cyclic GMP levels does not aid the diagnosis of malignancy or the detection of tumour metastases.

\section{References}

Bershtein, L. M., Semiglazov, V. F., and Valdina, E. A. (1976). The excretion of cyclic adenosine monophosphate (CAMP) in patients with cancer of the mammary gland and lung (Russian). Voprosy Onkologii, $22(8), 30-35$.

Brown, B. L., Albano, J. D. M., Ekins, R. P., Sgherzi, A. M., and Tampion,W. (1971). A simple and sensitive saturation assay method for the measurement of adenosine 3':5'-cyclic monophosphate. Biochemical Journal, 121, 561-562.
Criss, W. E., and Murad, F. (1976). Urinary excretion of cyclic guanosine $3^{\prime}: 5^{\prime}$-monophosphate and cyclic adenosine $3^{\prime}: 5^{\prime}$-monophosphate in rats bearing transplantable liver and kidney tumors. Cancer Research, 36, 1714-1716.

Criss, W. E., and Murad, F. (1977). Cyclic nucleotide metabolism in tumors. In Clinical Aspects of Cyclic Nucleotides, edited by L. Volicer, p. 429. Spectrum, New York.

Exton, J. H., Hardman, J. G., Williams, T. F., Sutherland, E. W., and Park, C. R. (1971). Effects of cyclic guanosine $3^{\prime}, 5^{\prime}$-monophosphate on the perfused rat liver. Journal of Biological Chemistry, 246, 2658-2664.

Gennari, C., Francini, G., Galli, M., and Lore, F. (1978). Urinary excretion of cyclic adenosine $3^{\prime}, 5^{\prime}$-monophosphate and cyclic guanosine $3^{\prime}, 5^{\prime}$-monophosphate in malignancy. Journal of Clinical Pathology, 31. 735-741.

Goldberg, N. D., and Haddox, M. K. (1977). Cyclic GMP metabolism and involvement in biological regulation. Annual Reviews in Biochemistry, 46, 823-896.

Goldberg, N. D., Haddox, M. K., Nicol, S. E., Glass, D. B., Sanford, C. H., Kuehl, F. A., Jr., and Estensen, R. (1975). Biologic regulation through opposing influences of cyclic GMP and cyclic AMP: the YinYang hypothesis. Advances in Cyclic Nucleotide Research, 5, 307-338.

Levine, R. A. (1973). The role of cyclic AMP and prostaglandins in hepatic and gastrointestinal functions. In Prostaglandins and Cyclic AMP: Biological Actions and Clinical Applications, edited by $\mathrm{R}$. $\mathrm{H}$. Kahn and W. E. M. Lands, pp. 75-117. Academic Press, New York.

Murad, F. (1978). Clinical applications of cyclic nucleotides. Presented at the First International Symposium 'Cyclic Nucleotides and Therapeutic Perspectives', Paris, July 1978.

Murad, F., Kimura, H., Hopkins, H. A., Looney, W. B., and Kovacs, C. J. (1975). Increased urinary excretion of cyclic guanosine monophosphate in rats bearing Morris hepatoma 3924A. Science, 190, 58-60.

Neethling, A. C., and Shanley, B. C. (1976). Cyclic GMP excretion and hepatoma (Letter). Lancet, $2,578$.

Vitek,V., Gill, W., Lang, D. J., Conn, A. K., and Cowley, R. A. (1976). Time-related response of urinary cyclic adenosine monophosphate to trauma. Surgery, Gynecology and Obstetrics, 143, 901-905.

Wood, P. J., and Marks, V. (1978). Direct measurement of CGMP in blood plasma and urine by radioimmunoassay. Annals of Clinical Biochemistry, 15, 25-30.

Requests for reprints to: Dr P. J. Wood, The University of Southampton, South Laboratory and Pathology Block, Level D, Southampton General Hospital, Tremona Road, Southampton SO9 4XY, UK. 